\title{
El dequeísmo: ¿un cambio en progreso de la sintaxis castellana?
}

\author{
Raymundo Casas Navarro \\ Universidad Nacional Mayor de San Marcos \\ casasnavarro1@hotmail.com
}

\begin{abstract}
Las lenguas siempre están en movimiento, ninguno de sus más mínimos detalles está fijo nunca, en todas ellas hay necesariamente puntos que pueden cambiar incluso en el transcurso de una sola generación. Ello es una consecuencia inevitable de la propia esencia del lenguaje...
\end{abstract}

Otto Jespersen

\section{Resumen}

El presente artículo aborda la naturaleza sintáctica del dequeísmo y trata de conjeturar los factores sociolinguiísticos involucrados en el fenómeno. De ese modo, se abandona la perspectiva fijista que observa el dequeísmo como una mera transgresión o como un caso de incorrección idiomática. En contraste con una cohorte de hipótesis pergeñadas en la literatura reciente, se ha logrado corroborar que el comportamiento dequeísta es una isoglosa innovadora en el mecanismo hipotáctico general de la lengua castellana. Se puede determinar que, para la cognición de un creciente grupo de hispanohablantes, la conjunción 'que' no es lo suficientemente nítida para satisfacer el operador hipotáctico fundamental de la subordinación sustantiva de la sintaxis castellana, razón por la cual el uso de la secuencia 'de que' para introducir cláusulas de subordinación sustantiva se puede entender como un cambio en progreso de la sintaxis castellana. De ese modo, se apunta a lograr una simetría óptima en el sistema hipotáctico de nuestra lengua. Con el fin de dilucidar los factores sociolinguísticos involucrados en el dequeísmo, hemos aplicado un test a un grupo de hablantes, aparentemente, muy 
innovador: los jóvenes de entre 15 y 25 años. Discutimos, en concreto, si las variables sexo y literacidad tienen un influjo significativo en el comportamiento dequeísta.

Palabras claves: Dequeísmo, factor sociolinguiístico, cambio en progreso, subordinación sustantiva.

\begin{abstract}
The purpose of this article is to understand the syntactic nature of the dequeismo as phenomenon of the Spanish and to determine their sociolinguistic factors involved. Thereby, we refuse the normative fixity that explains the dequeismo as a mere transgression or as a case of idiomatic incorrectness. In contrast with a cohort of hypothesis arranged in the recent literature, it has achieved to corroborate that the dequeista behavior is an innovative isogloss in the general mechanism of Spanish subordination. Considering some aspects of cognition, we support that for an increasing group of Spanish speakers the conjunction 'que' is not it sufficiently clear to satisfy the subordination operator of the substantive subordination in syntax Spanish. Indeed, the use of the sequence 'de que' introducing clauses of substantive subordination can be viewed as a change in progress of the Spanish. Thereby, one points out to achieve an ideal symmetry in the hypotactic system of our language. In order to explain the sociolinguistic factors involved in the dequeismo, we have applied a test to a group of speakers, seemingly, very innovative: the young persons of between 15 and 25 years old. We discuss if the variables sex and literacy have an influence in the dequeista behavior.
\end{abstract}

Key words: Dequeismo, queismo, sociolinguistic factor, change in progress, substantive subordination

Recibido: 28/10/15

Aceptado: 30/11/15

\title{
Prolegómenos
}

Como consideramos que el dequeísmo entraña un change in progress (una gramaticalización inacabada) en la sintaxis del castellano (en especial, en la región de la hipotaxis), trataremos de delinear los factores sociolinguíísticos comprometidos con la difusión y expansión de tal cambio. Ello presupone establecer el perfil formal de la subordinación en castellano, lo que se reflejará en la propuesta de un parser, esto es, de un analizador sintáctico.

En una primera aproximación, podemos estipular que el dequeísmo estriba en el empleo de la secuencia de que no prevista por la gramática del castellano 
estándar internalizada en la mente de hablantes conservadores. Por ejemplo, Pienso de que todo se va a solucionar pronto es una construcción dequeísta. Se debe señalar que hay secuencias de que previstas por la gramática estándar, de tal manera que Ella se enteró de que fuiste a la finca no es dequeísta. Es más, en el sistema estándar hay una serie de alternancias permitidas en las cuales se aceptan válidamente tanto el subordinante que solo como la secuencia de que. Así, (a) y (b) son oraciones consideradas correctas por la gramática normativa:

(a) Dudo mucho que acepten la propuesta.

(b) Dudo mucho de que acepten la propuesta.

En el nivel de la lengua oral empleado por muchos hispanohablantes (tanto de España como de América, tanto de la norma culta como del habla popular) se escuchan construcciones llamadas dequeístas como Creemos de que no hay equidad en el debate (emitida por una abogada limeña en un programa político televisivo en el contexto del referéndum para la alcaldía de Lima). Lo anterior revela que las construcciones dequeístas están haciendo cala profunda en nuestra lengua, razón por la cual urge estudiarlas de hito en hito.

En el ámbito de los estudios hispánicos, el dequeísmo se abordó como un problema de indagación en la década de 1960 y, sobre todo, en los países hispanoamericanos. Los lingüistas españoles, en un comienzo, no le prestaron demasiada atención. Sin embargo, como cuestión de hecho, el comportamiento dequeísta se puede retrotraer hasta etapas prístinas del castellano y ya se tiene noticia del fenómeno en el siglo XVIII. Con el correr del tiempo y en la medida en que se percibía un incremento del dequeísmo incluso en personas de la llamada norma culta (tanto en España como en América), surgió la necesidad de estudiar el fenómeno para comprender las razones de su uso y para proponer las llamadas medidas correctivas. Así pues, en una perspectiva clásica, el dequeísmo se abordó como un defecto o vicio del lenguaje, y se intentó dilucidarlo para coadyuvar a la tarea linguopedagógica de índole prescriptivista (Náñez 1984; Millán Ch. 1988, 1992, 1999-2000; Boretti de Macchia 1991, 1992; Carnicero Guerra 1992; Navarro 2005). Por más que el espíritu de tales indagaciones se rige por un criterio anacrónico y fijista, sus análisis no se pueden soslayar en la medida en que subtienden una comprensión del fenómeno, lo que no es de poco valor. La prescripción presupone una descripción previa que puede tener cierto valor heurístico. Por ejemplo, la explicación del dequeísmo como un fenómeno de hipercorrección recoge un proceso sintáctico por el cual la preposición de se incorpora (Baker 1988) a la frase verbal dequeísta (d) a partir de una frase nominal (c): 
(c) La promesa de su ayuda.

(d) Prometió de que ayudaría.

Dado que el dequeísmo se muestra como una conducta frecuente a partir de la década del 60 (al menos, a partir de ese momento se visibiliza con más intensidad), los gramáticos se han embarcado en un crucero que buscaba detener la propagación del fenómeno como un corolario de una visión fijista de la lengua. Así, se entendía que el dequeísmo se podía explicar en virtud de la elasticidad de la preposición 'de' y se percibía adecuadamente que la debilidad del subordinante que podía motorizar la inserción de un de expletivo. De modo paralelo, se observó la irrupción de otro fenómeno relacionado, llamado antidequeísmo o queísmo, y se describió la coaparición de ambos fenómenos en un esquema integrado:

\begin{tabular}{|c|c|}
\hline Construcciones dequeístas & Construcciones queístas \\
\hline Decir de que... & Alegrarse que... \\
\hline Pensar de que... & Asegurarse que... \\
\hline Creer de que... & Acordarse que... \\
\hline Suponer de que... & Olvidarse que... \\
\hline Recordar de que... & Convencerse que... \\
\hline
\end{tabular}

\begin{tabular}{|c|c|}
\hline Construcciones no dequeístas & Construcciones no queístas \\
\hline Decir que... & Alegrarse de que... \\
\hline Pensar que... & Asegurarse de que... \\
\hline Creer que... & Acordarse de que... \\
\hline Suponer que... & Olvidarse de que... \\
\hline Recordar que... & Convencerse de que... \\
\hline
\end{tabular}

En virtud de la plétora de estudios en torno al dequeísmo, la Real Academia Española no ha podido mantenerse al margen de la discusión y en el Diccionario panhispánico de dudas (2005: 214) estipula que el dequeísmo «es el uso indebido de la preposición de delante de la conjunción que cuando la preposición no viene exigida por ninguna palabra del enunciado». En la Nueva gramática (Real Academia Española 2009), incluso, se brinda todo un acápite al dequeísmo. El fenómeno se define de la siguiente manera (Real Academia Española 2009: 3248): 
(...) el uso incorrecto de la secuencia de que en las subordinadas sustantivas cuando la preposición de no está justificada en ellas desde el punto de vista gramatical, como en Creemos de que educándonos vamos a convivir mejor (CREA oral, Paraguay), frente a la variante correcta Creemos que educándonos vamos a convivir mejor.

Aunque la Nueva gramática sentencia que el dequeísmo es una incorrección, no lo considera agramatical, en la medida en que un buen grupo de hablantes construye oraciones que caen en esa categoría. También se arguye que el dequeísmo no goza de prestigio en la lengua culta, dado que se percibe como una conducta inelegante. Para explicar el fenómeno dequeísta, la Nueva gramática conjetura que algunos hablantes consideran necesaria una marca formal expresa para introducir los complementos y sujetos oracionales posverbales ante determinados predicados. Así, sugiere que los hablantes dequeístas interpretan que la conjunción que no identifica suficientemente la cláusula como subordinada, "por lo que agregan una partícula que haga esta relación más patente, a modo de marca de visibilidad» (Real Academia Española 2009: 3249). De manera timorata, la Nueva gramática se adhiere a la explicación que estipula la secuencia de que como una marca de evidencialidad en castellano.

También se ha explorado en una visión descriptivista que ha intentado presentar el dequeísmo como una conducta típica del habla culta en la península hispánica y en dialectos estándares hispanoamericanos (Bentivoglio 1976, 1980-1981; McLauchlan 1982; Boretti de Macchia 1989; Carbonero 1992; Rabanales 2005). Estos trabajos son muy útiles, puesto que dan una mirada comprensiva y apuntan a señalar que el dequeísmo tiende a una cierta normalización, dado que resulta muy difícil excluirlo de cualquier consideración objetiva sobre la llamada norma culta.

Una vertiente importante ha sido el estudio del dequeísmo desde una dimensión sociolinguiística, con lo cual se ha logrado apuntar los mecanismos de change in progress conjeturados, no sin una vena polémica, en varios estudios de teoría linguí́stica (Baker 1988; Campbell 2001; Newmeyer 2001; Bybee 2002; Bowers 2004). Sin intentar llegar a una mención exhaustiva, la concreción de esta nueva dimensión en los abordajes sobre el dequeísmo se dan en Bentivoglio \& D'Introno 1977; Bogard \& Company 1989; De Mello 1995; Bentivoglio \& Galué 1998-1999; Company 2001; Del Moral 2004; Cornillie \& Delbecque 2008; Delbecque 2008.

Nuestra investigación se funda en una tradición linguiística que trata de abordar los fenómenos sintácticos desde una perspectiva integradora y, por ello, se inspira en una serie de trabajos variados teóricamente (Chomsky 1999; Langacker 2000; Cullicover \& Jackendoff 2005; Assmann \& Weiser 2010), pero 
que convergen en una determinada visión de la gramática: el lenguaje propone herramientas para la interpretación y exhibe una propensión a la simetría. Como sugieren tan persuasivamente Smolensky y Legendre (2006), el uso del lenguaje se debe entender en el marco de una mente armónica que se rige por el criterio de la optimización en el siguiente sentido específico: el nivel simbólico de la experiencia humana se realiza en un sustrato conexionista gobernado por principios de procesamiento que maximizan la armonía entre los inputs y los outputs.

\section{Marco teórico}

El dequeísmo ha sido abordado, tradicionalmente, desde una perspectiva eminentemente purista y, en consecuencia, se ha definido como un error, una transgresión, una anomalía y hasta como un vicio. El anatema normativista ha sentenciado que el dequeísmo implica una construcción anómala, dado que no está prevista por la gramática normativa (mutatis mutandis, se dice lo mismo del queísmo). Sin embargo, el fenómeno dequeísta también se puede estudiar como un ejemplo de cambio sintáctico, una suerte de change in progress [cambio en progreso] que afecta la fisonomía gramatical del castellano. Luego de muchos años de aproximaciones, se puede constatar que las estructuras dequeístas (consideradas anómalas por la gramática normativa) revelan un cambio en marcha que opera en el mecanismo de la hipotaxis castellana: la secuencia de que ha devenido en un operador de subordinación en la gramática mental de muchos hablantes del castellano. Se trata de un cambio vertiginoso que ha trascendido la oralidad (ya se encuentra en la lengua escrita) y ya no se puede sostener plausiblemente que sea un fenómeno basilectal (el dequeísmo se observa en las conductas de los hablantes de la llamada norma culta). Sin embargo, hay factores sociolinguiísticos que morigeran el flujo del cambio y establecen una aguda tensión entre las fuerzas centrífugas (la propensión al cambio) y las fuerzas centrípetas (la conservación del statu quo idiomático). Nos interesa, sobremanera, identificar los factores que retardan el cambio. En consecuencia, desarrollaremos una investigación que pueda conjeturar una correlación entre el grado del dequeísmo y ciertas variables sociolinguiísticas como sexo, edad y literacidad.

En un trabajo inserto en las primeras versiones de la gramática generativa, Violeta Demonte (1982) logró dilucidar la estructura básica de la subordinación sustantiva. La idea generalizada consideraba que las cláusulas sustantivas se introducían por medio de una partícula desposeída de significado y de función (excepto la de puro nexo): la denominada conjunción subordinante que. Asimis- 
mo, se entendía que la conjunción que era un nominalizador en la medida en que transpone (es un transpositor) una oración (O) en una frase nominal (FN). Demonte da razones sólidas para inclinarse por la hipótesis lexicista, según la cual la partícula que pertenece a una regla de estructura sintagmática (Bresnan 1972; Noonan 1979):

$$
\mathrm{O}^{\prime} \rightarrow \text { SUB O }
$$

El constructo anterior permite dar cuenta formal de un enunciado típico de un hispanohablante como Dijo que Luis llegará el miércoles.

Ahora bien, desde el clásico trabajo seminal de Chomsky (1975), se ha determinado que el objetivo de la teoría linguística es ofrecer explicaciones formales para dar cuenta de las intuiciones de los hablantes nativos. Asimismo, un criterio de bondad epistemológica es operar con la navaja de Occam y tratar de depurar lo más posible el formalismo teórico con el fin de explicar, de la manera más simple posible, las intuiciones de los hablantes. En este crucero, Cullicover y Jackendoff (2005) proponen el modelo sintáctico más simple de acuerdo con el siguiente principio: la sintaxis provee la mínima estructura necesaria para mediar entre el polo fonológico y el polo semántico. Esta concepción propone la hipótesis de la caja de herramientas para entender que la interfaz entre sintaxis y semántica debe ser muy simple, de tal modo que el significado se proyecte con transparencia en la estructura sintáctica y esa proyección sea uniforme en alto grado. Intuitivamente, la gramática universal provee un conjunto de herramientas y la sintaxis de una lengua determinada hará uso de una herramienta específica para efectuar la mediación entre el significado (la forma lógica) y el sonido (la forma fonética).

Aplicando este marco a nuestro problema de investigación, se puede determinar que en las estructuras sintácticas de la subordinación sustantiva en castellano es crucial que el operador de subordinación (SUB) se refleje con transparencia y con uniformidad, lo que no ocurre precisamente en la gramática estándar vigente de nuestra lengua. Pensamos que aquí está el germen para que una buena cantidad de hispanohablantes haya interpretado computacionalmente la necesidad de reforzar el operador de subordinación con el fin de hacerlo más transparente y uniforme, de acuerdo con la concepción de la hipótesis de la caja de herramientas. Es decir, esos hablantes han recurrido computacionalmente a la caja de herramientas para encontrar un mecanismo de subordinación más nítido y más uniforme. Así, la opacidad del sistema hipotáctico de la lengua estándar ha generado esta búsqueda computacional, que puede ser explicada en términos de la sintaxis minimista (Eguren y Soriano 2004). 
En el programa minimista (Chomsky 1999) se parte de una selección específica de materiales del lexicón para que el sistema computacional pueda construir las estructuras sintácticas. La construcción se rige por una aplicación sucesiva de operaciones simples que conducen hasta la forma lógica (FL). En un punto cualquiera de la derivación, se efectúa la bifurcación hacia la forma fonética (FF). La derivación converge en la FF si la FF consta solo de objetos fonéticos legítimos. La derivación converge en la FL si la FL consta de objetos legítimos en ese nivel. La derivación converge íntegramente si lo hace en los dos niveles.

Frente a los modelos anteriores de la gramática generativa como el de Principios y Parámetros (P\&P), el programa minimista (PM) se presenta como menos barroco para guardar consonancia con lo que se puede denominar el compromiso biolinguístico: asumir que la lengua es un fenómeno biológico singular, con una estructura de simplicidad y elegancia inusitada. El contraste se puede hacer visible en el siguiente esquema

Modelo generativo de P\&P

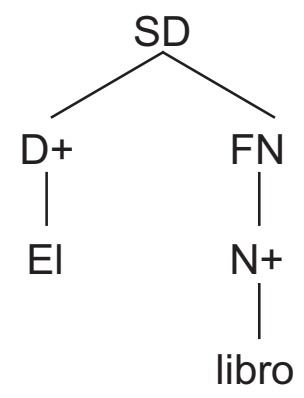

Modelo de PM

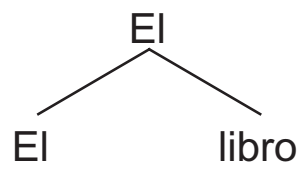

La primera operación es la selección arbitraria de materiales léxicos, esto es, conjuntos de rasgos fonológicos (interpretables en la FF), rasgos semánticos y rasgos formales (interpretables en la FL). Aunque los rasgos formales no figuran en la derivación fonética, desempeñan un papel importante en la derivación sintáctica. Hay rasgos formales intrínsecos como el verbo y rasgos formales opcionales como el tiempo; del mismo modo, hay rasgos formales interpretables como el número y rasgos formales no interpretables como el caso. Así cuando se selecciona un elemento del lexicón, se seleccionan sus rasgos intrínsecos y sus rasgos opcionales pertinentes (por ello, se puede seleccionar un elemento como 'compró' o 'compraba'). 
Chomsky crea el neologismo 'numeración' para designar el conjunto inicial seleccionado a partir del lexicón. A partir de la numeración, se construyen estructuras sintácticas por medio de las operaciones de ensamble y movimiento. Esta fase de derivaciones llega hasta el nivel de la FF y de la FL para establecer si hay o no convergencia. Si la derivación no se estrella, el resultado es legible tanto fonéticamente como semánticamente, lo que permite la interpretación plena. En la ruta, puede haber un paso que estrelle la derivación y, como efecto, resulta una estructura ilegible ora en la FF, ora en la FL. Por ejemplo, a partir de la numeración \{Raúl, vende, caramelos\}, se puede tener esta sucesión de derivaciones por ensamble (Merge):

\{vende $\{$ vende, caramelos\}

\{vende $\{$ Raúl $\{$ vende vende, caramelos\}\}\}\}

La operación ensamble no tiene restricciones formales. Si se aplica mal, simplemente no habrá convergencia.

\section{Explicación del dequeísmo}

En primer término, indagamos sobre el mecanismo sintáctico involucrado en el dequeísmo, un cambio que se da en la lengua castellana y que se puede entender como un fenómeno progresivo, es decir, como una gramaticalización inacabada. De esa manera queremos resolver un problema de análisis sintáctico: ¿en qué medida el dequeísmo evidencia un nuevo mecanismo hipotáctico en la lengua castellana?

Dado que la escisión de la sintaxis española entre hablantes dequeístas (dialecto innovador) y hablantes no dequeístas (dialecto conservador) configura una alternancia variacionista, se debe explicar en términos de una teoría del cambio sintáctico. Ya en las Conferencias de Aarhus de 1934, Louis Hjelmslev (1976) estableció la explicación de la dinámica del sistema, teoría que puede tornar inteligible el fenómeno del dequeísmo. De acuerdo con las lecciones de Hjelmslev, todo sistema exhibe una propensión al optimum, lo que sirve para borrar la fuerte antinomia de Saussure entre diacronía y sincronía, dado que la lengua como sistema (eje sincrónico) y la lengua como desarrollo (eje diacrónico) son fenómenos solidarios. Así, la teleonomía de la lengua no puede admitir opacidades en el seno del sistema, razón por la cual el cambio linguí́stico se explica partiendo del sistema linguí́stico y el sistema linguístico se explica partiendo del cambio linguíístico. Ello quiere decir que, en la dinámica del lenguaje, hay una tensión entre la necesidad del hablante (el mínimo esfuerzo articulatorio) y la necesidad del oyente (la máxima nitidez perceptiva). Esta tensión 
acarrea que se produzcan cambios linguiísticos que tienden a la optimidad de la interpretación, lo que Langacker (2000) denomina principio de transparencia.

El elemento SUB del castellano estándar se satisface con un conjunto de requisitos que es satisfecho por un solo elemento tenue como la conjunción que. Además, hay varias alternancias permitidas por el propio sistema que lo hacen más borroso y poco transparente. Así, se ha creado el caldo de cultivo para la emergencia de un cambio que responde al esfuerzo constante de la lengua hacia la simetría y la transparencia. Por ello, la presencia del dequeísmo se inició como una innovación prístina que ha ganado adeptos con el tiempo. De tal modo que llegamos a esta situación:

EL DIALECTO CONSERVADOR (no dequeísta): Dijo que Carlos leyó el libro

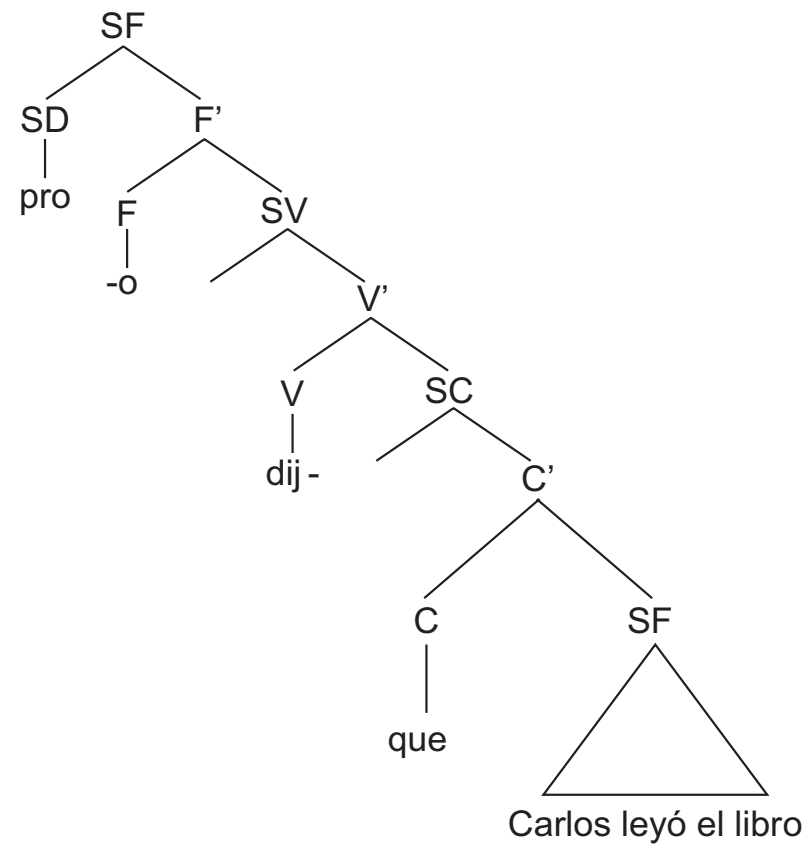

En el dialecto conservador, el sintagma complementante (SC) inserta un elemento subordinante 'que' (complementizador) que introduce la cláusula subordinada (Carlos leyó el libro). Para este grupo de hispanohablantes, basta con el nexo 'que' para que la derivación de la subordinación converja 
legítimamente. Para estos hablantes, la inserción de un elemento 'de' en esta estructura sintáctica es ilegítima y ello explicaría formalmente por qué consideran una oración dequeísta como inelegante.

\section{EL DIALECTO INNOVADOR (DEQUEÍSTA): Dijo de que Carlos leyó el libro}

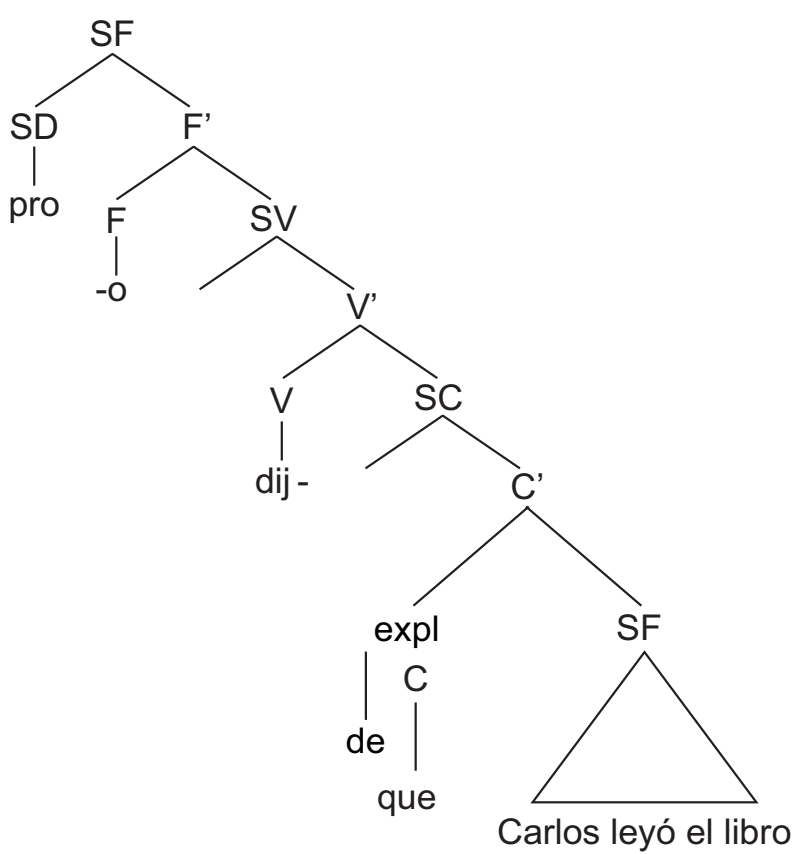

Desde el punto de vista sintáctico, la innovación dequeísta implica la inserción de un 'de' expletivo con el objetivo de fortalecer el operador de subordinación. Cabe recordar que la gramática castellana recurre a los expletivos (verbigracia la conspicua negación expletiva de «No me iré de aquí hasta que no me digas la verdad»), razón por la cual no hay aquí ninguna hipótesis ad hoc.

Así, pues, en las oraciones de subordinación sustantiva aparece en la numeración un elemento como SUB(ordinación): $\{$ yo, creo, SUB, $\{\gamma\}$ \}. Lo anterior se adjunta a una cláusula (derivada por fases a partir de otra numeración) como Carlos leyó el libro. Si representamos la cláusula con un símbolo arbitrario $(\gamma)$, se obtiene lo siguiente: 


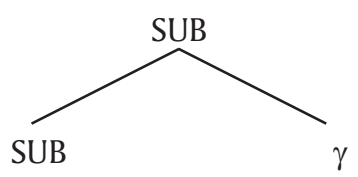

Para converger, los rasgos de SUB deben cancelarse por un elemento subordinante. La cancelación está motivada por propiedades morfológicas. Dado que, en el programa minimista, la sintaxis se reduce a operaciones y principios muy simples, la alternancia entre Dijo que Carlos leyó el libro y Dijo de que Carlos leyó el libro se explica por la recurrencia a dos numeraciones distintas. En virtud de este escueto aparato teórico, se postula que para los hablantes dequeístas la conjunción que no sirve por sí sola para cancelar los rasgos de SUB. Ello puede ocurrir cuando un elemento como que sufre un proceso de desgaste por el hecho de tener un valor polifuncional en el sistema computacional. Así, en los hablantes dequeístas, se inserta jerárquicamente una pseudopreposición de como un expletivo que satisface los requisitos de SUB. Se podría pensar que este elemento de debe cumplir con criterios semánticos o pragmáticos, pero los datos disponibles no permiten aseverar fuertemente ninguna propuesta en este sentido.

De este modo, el dequeísmo se puede definir como la propensión a insertar la partícula de ante el nexo subordinante que (interpretado como muy débil para satisfacer por sí solo los rasgos de SUB) en las oraciones castellanas de subordinación sustantiva. En virtud de que este comportamiento está muy extendido en el eje diatópico y en el eje diastrático de la lengua castellana y en virtud de que es una solución innovadora a un problema real del sistema estándar castellano, una oración típicamente dequeísta (verbigracia Creo de que todo va a mejorar) ya no debería marcarse con el asterisco (*), señal de agramaticalidad. En lugar de ver el dequeísmo como una anomalía, debe entenderse como la emergencia de un nuevo patrón castellano: la secuencia DE QUE funciona como un operador general de hipotaxis. En tal sentido, los datos sugieren abductivamente la siguiente hipótesis:

Las conductas dequeístas exhiben un nuevo mecanismo hipotáctico que ha surgido por una propensión del sistema hacia la simetría. La manera como se puede dar cuenta de este fenómeno puede recurrir al constructo de reanálisis o de exaptación. En efecto, la partícula «de» que aparece en las construcciones dequeístas no es una preposición real, sino una partícula que ayuda a satisfacer con transparencia los requisitos de SUB.

Un corolario de la anterior hipótesis estriba en considerar la interacción entre factores cognitivos y estructuraciones linguísticas, de acuerdo con el marco de Langacker (2000) y de Cullicover \& Jackendoff (2005). 
La mente humana trabaja con un patrón de armonía que es satisfecho cuando las lenguas humanas llegan o tienden al optimum. Si el sistema linguiístico se aleja de ese optimum, habrá una tendencia inmanente para restablecer la armonía perdida o resquebrajada.

En una construcción como "Luis dijo de que estaba en el cine», la partícula 'de' es un expletivo, esto es, ha sufrido una decoloración [bleaching], por la cual ha perdido su valor de preposición, como prevé la teoría de la gramaticalización. En la cognición de los hablantes dequeístas, la preposición 'de' se reanaliza y deviene en un expletivo. En efecto, los hablantes dequeístas no hacen el cómputo de la partícula 'de' como una preposición y, por ello, establecen la relación entre las siguientes construcciones:

(e) Luis dijo de que estaban en el cine.

(f) Luis lo dijo.

El hecho de que los hablantes dequeístas pronominalicen la oración (e) en términos de (f) revela nítidamente que 'de' no es una preposición, sino simplemente un expletivo o una partícula que ha sufrido una exaptación.

En un artículo sumamente interesante, Demonte \& Fernández Soriano (2004) aluden a una explicación del dequeísmo en términos de factividad y la rechazan categóricamente. En efecto, la ruta de la factividad no parece promisoria. Desde el clásico trabajo de Kiparsky \& Kiparsky (1967), se establece que un verbo factivo presupone que su complemento es verdadero, razón por la cual el valor de verdad de la cláusula completiva preserva su valor de verdad, así se niegue la cláusula introductoria.

Así, 'afirmar' no es un verbo factivo por cuanto no desarrolla esa presuposición. Si enuncio Afirmo que Raúl es un cínico, le doy un valor de verdad a la cláusula completiva (Raúl es un cínico); pero si niego mi enunciado (No afirmo que Raúl sea un cínico) se cambia el valor de verdad de la cláusula completiva.

Ahora bien, 'lamentar' sí es un verbo factivo porque establece la presuposición explicada. Si profiero Lamento que Raúl sea un cínico, el valor de verdad de la cláusula completiva no cambia así yo niegue mi enunciado (No lamento que Raúl sea un cínico). Pues bien, se podría pensar que la factividad ayuda a explicar el fenómeno del dequeísmo, pero ese no es el caso porque los verbos factivos se pueden construir directamente con que o con la secuencia de que en la sintaxis estándar del castellano. Así, Él descubrió que lo habían engañado es factivo como lo es también Él se dio cuenta de que lo habían engañado.

Los estudios sobre el dequeísmo que han ido más allá del mero anatema y de la descripción meramente taxonómica han encontrado una veta muy in- 
teresante para explicar el fenómeno en términos de evidencialidad. Así, se ha logrado insertar la discusión sobre el dequeísmo en el mismo seno de la teoría linguíística, con lo que se ha generado un cambio de marcha saludable en torno a este fenómeno. Así, autores como Schwenter (1999), Sánchez Arroba (2001), Guirado (2006) y Demonte \& Fernández Soriano (2004) se embarcan por este crucero con argumentos muy sólidos desde el punto de vista teórico. La propuesta de Schwenter (1999) consiste en conjeturar que la partícula de en las estructuras dequeístas se explica por el rasgo de evidencialidad, entendida como una marca de distanciamiento frente a lo dicho: el hablante emplea la secuencia de que en el marco dequeísta para no comprometerse con el contenido de la cláusula. Así, se puede explicar el comportamiento del hablante dequeísta como una búsqueda de una marca evidencial para indicar inseguridad, evento no experimentado, desacuerdo, falta de compromiso, entre otras connotaciones semánticas. Así, esta hipótesis predice que una estructura como Él dice de que Carlos fue a la reunión será más frecuente que una estructura como Yo digo de que Carlos fue a la reunión. Lamentablemente, los datos empíricos o no establecen la verdad de esa predicción, o son muy ambiguos al respecto. Demonte \& Fernández Soriano (2004), en esta misma línea de pensamiento, conjeturan que en castellano COMP es un real complementizador que puede tener además otros rasgos: fuerza, factividad, credibilidad y evidencialidad. Ahora bien, ellas postulan que en el dialecto estándar que amalgama todos estos valores, pero en el dialecto dequeísta la partícula de (que se sitúa en el núcleo de una categoría funcional más arriba que la conjunción que) tiene un rasgo semántico de evidencialidad (refleja el juicio del hablante sobre una baja confiabilidad).

\section{Hipótesis de Demonte \& Fernández Soriano}

Dialecto estándar

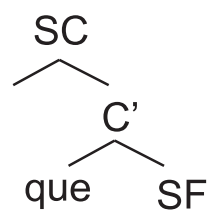

Dialecto dequeísta

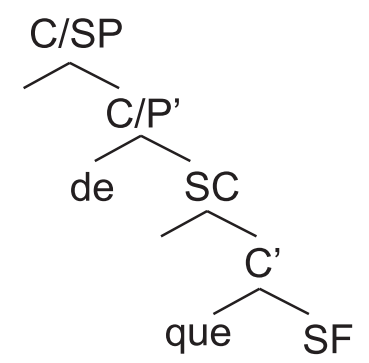


La piedra de toque de esta hipótesis es que predice la ocurrencia nula de una secuencia dequeísta como Es evidente de que si te callas todo será mucho peor. En nuestro estudio, nosotros hemos encontrado una buena frecuencia para enunciados dequeístas como Es evidente de que todo marcha bien cuando se planifica y Por supuesto de que todo ocurrió como estaba previsto. En rigor, tales construcciones se dan y, prima facie, establecen ciertas fisuras en la hipótesis de la evidencialidad como factor determinante en el dequeísmo. La única salida para dar cuenta de estos fenómenos recalcitrantes para una teoría de la evidencialidad es el expediente ad hoc de que la confusión se puede deber a la fuerte presión normativista, pero se trata de una respuesta muy poco convincente y nada promisoria. Solo queda proseguir con la investigación y estudiar el fenómeno con nuevos datos y con una nueva interpretación.

\section{Consideraciones sociolingüí́sticas}

En la teoría del cambio, se incide en la gradualidad, esto es, en la relativa lentitud de los cambios. La propagación del cambio sigue un ritmo, al parecer, inexorable, pero que puede ser ralentizado por ciertos factores. Con el fin de percibir claramente la fuerza de la innovación dequeísta en su tensión con la fuerza centrípeta, elegimos encauzar nuestra indagación a un grupo etario determinado: los jóvenes de entre 15 a 25 años. La suposición inicial entrañaba que los jóvenes constituyen un grupo innovador en la medida en que suelen ser refractarios a las normas. A su vez, como queríamos evaluar la influencia de variables como saber gramatical o literacidad, enfocamos nuestra atención hacia un grupo especial de jóvenes: los estudiantes. ¿Por qué nos embarcamos en este crucero?

En una excelente conferencia (Escobar 1987), el maestro Alberto Escobar explicaba un agudo contraste ocurrido en la ciudad de Lima. Hasta los años sesenta, la actitud de los hablantes limeños se regía por la puritas idiomática, de modo tal que se proyectaba una jerarquía entre los que hablaban 'bien' y los que no lo hacían tan 'bien' en un sentido determinado: los que sentían que no hablaban tan 'bien' aspiraban a llegar a la cima de la puritas, de acuerdo con la ideología del hablar bien el español. Y si no lo lograban, tenían el sentimiento de culpa de quien se sabe que está en falta. En cambio, argumenta Escobar, a partir de los setenta este panorama ideológico sufre una gran transformación y se instaura la ruptura del contravalor que, en términos linguiísticos, implica abandonar el ideal de la puritas idiomática. Se instaura una actitud centrada en la indiferencia frente a la norma y se pierde el valor de la corrección idiomática. Así, quienes hablan no tan 'bien' no guardan en su seno ningún sentimiento 
de culpa y esta actitud se ve plasmada, sobre todo, en los jóvenes quienes se liberan de las represiones y hablan conforme a su propio ritmo.

A partir de la hipótesis de Alberto Escobar, podríamos entender por qué la propensión al dequeísmo se ha acentuado en las últimas décadas y cabría pensar que son los jóvenes los principales impulsores del cambio. Ahora bien, dado que queremos establecer los factores que retardan el cambio, hemos decidido aplicar una encuesta gramatical y sociolinguística al grupo de jóvenes ${ }^{1}$, en principio, más influido por las presuntas variables que morigeran el cambio.

Dado que el grupo de jóvenes más innovador es el más alejado de las instituciones educativas, ello podría explicar por qué no hemos encontrado en el análisis hecho a los jóvenes estudiantes ningún sujeto que exhiba el dequeísmo masivo (constructo que hemos propuesto como un mecanismo heurístico para entender la intensificación en la dinámica del cambio).

En total, entrevistamos a 102 sujetos (49 hombres y 53 mujeres). 33 entrevistados correspondían al nivel de educación secundaria; 24 , al nivel preuniversitario; 28, al primer ciclo universitario (Facultad de Letras de la UNMSM); 17, al décimo ciclo universitario (Facultad de Educación de la UNMSM). El test fue anónimo para evitar un factor de distorsión que pudiera desalentar la mayor veracidad en las respuestas. La parte sociolinguística fue mínima y tuvo como cometido obtener datos fiables. El test de información gramatical siguió el criterio de simplicidad metodológica y consistió en preguntar sobre el estatuto gramatical de veinte enunciados con hipotaxis. Cada ítem presentaba la versión estándar del enunciado y la versión innovadora (dequeísta) con una posición aleatoria para evitar que la respuesta tenga un sesgo no atingente. El formato era de triple opción: el estudiante tenía que apoyarse en su intuición linguiística para elegir la versión y podía responder que las dos versiones le parecían correctas. Se tuvo especial cuidado en dar las mismas indicaciones y, sobre todo, impetrar que las respuestas se hagan solamente en función de la propia intuición del hablante. Pensamos que el carácter anónimo y el escrúpulo en las indicaciones nos dan la seguridad de contar con datos fiables para nuestras interpretaciones.

La aplicación del test permitió establecer el grado de fuerza de la conducta dequeísta. Se sabe que en el habla oral hay una plétora de estos fenómenos,

1 Este trabajo se inició en un seminario doctoral dirigido por el Dr. Félix Quesada, quien nos brindó comentarios sustantivos para encaminarlo bien. Después se desarrolló gracias a una investigación financiada por la Universidad Nacional Mayor de San Marcos y llevada a cabo en el seno del Instituto de Investigaciones Linguísticas (INVEL). En el desarrollo, participaron protagónicamente los jóvenes investigadores Giuseppe Collazos y Gema Silva. 
explicable por la espontaneidad y el automatismo de la oralidad. Por ello, quisimos calibrar hasta qué punto se ha extendido el dequeísmo con un instrumento muy seguro. Dado que los sujetos examinados han tenido tiempo para procesar mejor sus intuiciones, los datos obtenidos son más confiables que los que se pueden obtener en la lengua oral. En efecto, hemos querido establecer el grado de firmeza de estos cambios, lo que resulta muy discutible con datos puramente orales. Gracias a un constructo que propusimos (dequeísmo masivo), hemos podido establecer grados de dequeísmo, de acuerdo con ciertas estructuras que refuerzan la tendencia al dequeísmo. Aunque no hemos encontrado en el grupo examinado sujetos definidos por ese constructo, sí hemos hallado sujetos con fuerte propensión al dequeísmo (10.78\%). No se ha observado con fuerte evidencia que la variable sexo sea un factor que opere en el dequeísmo. En la aplicación del test que hemos llevado a cabo, se establece que las mujeres exhiben una retracción en la propensión al dequeísmo, pero no muy superior a la que exhiben los hombres. El grado de literacidad tampoco se perfila como un factor determinante de retracción, aunque no se ha podido determinar este influjo (o falta de influjo) debido a que la gran mayoría de estudiantes se autopercibe como anclado en una baja literacidad. El factor de mayor retracción es lo que se puede definir como saber gramatical (esto es, un conocimiento sustentado en la cantidad de cursos de gramática normativa seguidos por los hablantes).

El hecho de que la variable 'saber gramatical' sea el único factor involucrado significativamente en la propensión al dequeísmo nos induce a pensar que la presión normativista es la mayor responsable de la fuerza centrípeta que se opone al cambio. Esto quiere decir que en los hablantes más vinculados con la esfera escolar hallaremos a los sujetos más conservadores; en cambio, cabe colegir que el dequeísmo se manifestará más rotundamente en los hablantes más alejados de la presión normativista. Se puede postular, en consecuencia, que el dequeísmo masivo se hallará en ese grupo de hablantes.

Así, la variable de género no tiene mayor intrusión en la plasmación del dequeísmo y lo mismo se puede decir de la variable ligada a la literacidad, definida como un hábito frecuente de lectura. La aplicación de la encuesta determina que tanto hombres como mujeres muestran una propensión similar, y asimismo el nivel de lecturas (alto, medio o bajo) no se vincula con la tendencia a exhibir dequeísmo en las construcciones sintácticas.

Podemos sistematizar los datos hallados en los siguientes cuadros: 
Cuadro 1

\begin{tabular}{|c|c|c|}
\hline $\begin{array}{c}\text { FUERTE PROPENSIÓN AL } \\
\text { DEQUEÍSMO }\end{array}$ & $\begin{array}{c}\text { BAJA PROPENSIÓN AL } \\
\text { DEQUEÍSMO }\end{array}$ & $\begin{array}{c}\text { AUSENCIA DE } \\
\text { DEQUEÍSMO }\end{array}$ \\
\hline $11 \%$ & $57 \%$ & $32 \%$ \\
\hline
\end{tabular}

El 11\% de los sujetos exhibe una fuerte propensión al dequeísmo sin llegar al nivel del dequeísmo masivo. Ello quiere decir que, en estos sujetos, un alto número de estructuras oracionales se adscribe al formato dequeísta. El 57\% de los sujetos evidenció una baja propensión (menos de la mitad de estructuras gramaticales) y el $32 \%$ de los sujetos se comportó de acuerdo con el formato conservador de hablante no dequeísta.

\section{Cuadro 2}

\begin{tabular}{|c|c|c|}
\hline Alta literacidad & No dequeísmo & Correlación no significativa \\
\hline Género femenino & No dequeísmo & Muy baja correlación \\
\hline Saberes gramaticales & No dequeísmo & Correlación significativa \\
\hline
\end{tabular}

Entre los sujetos investigados que muestran ausencia de dequeísmo, no se ha encontrado una correlación significativa con la alta literacidad (es decir, intenso hábito de lectura). Asimismo, ha habido una bajísima correlación con el género femenino, lo que bien podría interpretarse como una refutación parcial de la hipótesis que propugna el conservadurismo linguiístico de las mujeres, como se señala en algunos estudios de sociolinguiística interaccional (Blas Arroyo 2012). Sí se ha encontrado una correlación significativa entre el no dequeísmo y una variable que se puede definir como 'saberes gramaticales' (esto es, haber participado en varios cursos sobre gramática normativa de la lengua española). Así, se puede proponer una estratificación de hablantes no dequeístas en función de esa variable. Por ejemplo, los sujetos de nivel secundario se encuentran en el nivel más bajo de no dequeísmo y los sujetos del décimo ciclo de nivel universitario ostentan el nivel más alto de no dequeísmo.

\section{Coda}

Los resultados de la presente investigación pueden ser de gran ayuda para repensar el enfoque más promisorio sobre la corrección idiomática. El anatema furibundo en contra del dequeísmo (considerarlo inelegante, defectuoso, 
anómalo o vicioso) ya no se puede sostener plausiblemente. Hay una opacidad en el mecanismo hipotáctico del castellano y ello explica la eclosión y el crecimiento del dequeísmo, como una forma de dotar de transparencia (Langacker 2000) al operador de subordinación sustantiva. La perspectiva sancionadora sobre el dequeísmo no se puede defender racionalmente, dado que es un prejuicio sustentado en la mera nesciencia. Por ello, el estudio que hemos realizado puede dar un sustento para un cambio de actitud: los educadores y el público en general deben ampliar sus miras para ir más allá del clásico anatema prescriptivista. Con bases científicas, creemos que debe entenderse que el cambio es un factor esencial en el lenguaje y que responde a las propias exigencias del sistema linguístico. En particular, los principios de propensión a la simetría y de superación de la opacidad están involucrados en la corriente linguística que conduce al dequeísmo. El conocimiento de estos constructos permitirá tener una visión más tolerante, alejada del ignaro prejuicio y la estólida estigmatización; así la linguística teórica brindará herramientas a los pedagogos para que se embarquen en un crucero que los pueda sacar del normativismo retrógrado que, desde antiguo, quiere hacer lo imposible: detener la mutación en la lengua. Nuestro estudio sirve, pues, para comprender que el criterio de corrección es moldeable, flexible y versátil; de allí su importancia práctica y su sello de repercusión social.

El estudio sobre el dequeísmo permitirá que los profesores, escritores y hablantes puedan eludir el influjo de los «expertos» del lenguaje, como los llama irónicamente Pinker (1999). Nuestro objetivo es que los pedagogos puedan despertar del sueño dogmático de fijar la lengua, de perpetuar la lengua estándar, y de convertir una clase de lengua castellana en una retahíla de anatemas. ¿Qué es lo correcto? Desde el punto de vista linguístico, como dice Pinker (1999: 407), «[l]a única manera de determinar si una frase es correcta o incorrecta gramaticalmente es buscar hablantes de una lengua y preguntárselo». Así, un lingüista podrá determinar que un enunciado como *Pienso que de estás equivocado es agramatical, pero deberá admitir la gramaticalidad del enunciado dequeísta Pienso de que estás equivocado, así como la gramaticalidad del enunciado estándar Pienso que estás equivocado. Hay muchos "expertos» en lenguaje que sancionan lo que ellos consideran «mala gramática» y sentencian que unos hablantes cometen errores garrafales, cuando en realidad solo hay un mal análisis de los fenómenos linguísticos. En rigor, nada de rescatable hay en esa censura porque, como dice Pinker, esos presuntos expertos «huelen a muerto, son los depositarios de lo que hay inútil en el lenguaje» (Pinker 1999: 410). La aplicación práctica de nuestra investigación tiene que ver con la necesidad de redefinir la norma y los criterios de corrección idiomática. Antes que lanzar normas rígidas que van en contra del flujo y reflujo de las lenguas, los 
maestros deben encaminarse por una reflexión prudente sobre la estructura y funcionamiento del lenguaje, y recordar, como hace Jackendoff (2010), que la comunicación verbal no es una calle de un solo sentido.

\section{Referencias bibliográficas}

ASSMANN, A., Georgi, D. \& Weisser, Ph. (2010). A Minimalist Analysis of Noun Incorporation. ConSOLE XIX, Groningen January 7th, 2010

BAKER, M. (1988). Incorporation. A Theory of Grammatical Function Changing. Chicago and London: The University of Chicago Press.

BENTIVOGLIO, P. (1976). "Queísmo y dequeísmo en el habla culta de Caracas". In Colloquium on Hispanic Linguistics (pp.1-18). Washington: Georgetown University Press.

BENTIVOGLIO, P. (1980-81). “El dequeísmo en Venezuela: ¿Un caso de ultracorrección?” en Boletín de Filología de la Universidad de Santiago de Chile, 31, pp. 705-19.

BENTIVOGLIO, P. \& D’Introno, F. (1977). "Análisis socio-linguiístico del dequeísmo en el habla culta de Caracas" en Boletín de la Academia Puertorriqueña de la Lengua Española, 6, pp. 58-82.

BENTIVOGLIO, P. \& Galué, D. (1998-99). “Ausencia y presencia de la preposición de ante cláusulas encabezadas por que en el español de Caracas: un análisis variacionista” en Boletín de Filología de la Universidad de Santiago de Chile, 37, pp.139-59.

BLAS ARROYO, J. L. (2012). Sociolingüística del español. Madrid: Cátedra.

BOGARD, S. \& Company, C. (1989). "Estructura y evolución de las oraciones completivas de sustantivo” en Romance Philology XLIII, 2, pp. 258-73.

BORETTI DE MACCHIA, S. (1989). "De(queísmo) en el habla culta de Rosario” en Anuario de Lingüística Hispánica, 5, pp. 27-49.

BORETTI DE MACCHIA, S. (1991). “(Des)uso preposicional ante que relativo”. In C. Hernández, G. de Granda, C. Hoyos, V. Fernández, D. Dietrick, \& Y. Carballera (eds.), El Español de América 1 (pp. 445-55). Valladolid: Universidad de Valladolid, Secretariado de Publicaciones.

BORETTI DE MACCHIA, S. (1992). "Queísmo y dequeísmo en el sociolecto medio: Un caso de hipercorrección” en O. Kovacci (ed.): Actas Jornada de Gramática V Centenario de la Gramática de la Lengua Castellana de Elio Antonio de Nebrija, (pp. 47-55). Buenos Aires: Facultad de Filosofía y Letras. Universidad de Buenos Aires.

BOWERS, J. (2004). Toward a Unified Theory of Argument Structure and Grammatical Function Changing Morphology. Workshop on Argument Structure. University of Tromsø.

BRESNAN, J. (1972). Theory of Complementation in English Syntax. Disertación doctoral. MIT.

BYBEE, J. (2002). "Cognitive processes in grammaticalization” in M. Tomasello (Ed.) The New Psychology of Language. New Jersey: Lawrence Erlbaum Associate Inc. 
CAMPBELL, L. (2001). "What's wrong with grammaticalization?" in Language Sciences 23. $113-161$.

CARBONERO, P. (1992). "Queísmo y dequeísmo en el habla culta de Sevilla: Análisis contrastado con otras hablas peninsulares y americanas" en Scripta Philologica in Honorem Juan M. Lope Blanch. A los 40 años de la UNAM y a los 65 años de vida (pp.43-63) México: Universidad Nacional Autónoma de México.

CARNICERO GUERRA, Angel. (1992). “(De)queísmo y cuestiones afines en el habla popular de Sevilla y San Juan de Puerto Rico" en El español de América: Actas del IV Congreso Internacional del Español de América (pp. 622-637). Santiago: Mar del Plata.

CHOMSKY, N. (1975). The Logical Structure of Linguistic Theory. Chicago: Chicago University Press.

CHOMSKY, N. (1999). El programa minimalista. Madrid: Alianza Editorial.

Company Company, C. (2001). "Multiple dative-marking grammaticalization. Spanish as a special kind of primary object language" in Studies in Language 25, 1. pp. 1-46.

CORNILLIE, B. \& Delbecque, N. (2008). "Speaker Commitment: Back to the speaker. Evidence from spanish alternations" in Belgian Journal of Linguistics 22. John Benjamins Publishing Company. pp. 37-62.

CULLICOVER, P. \& Jackendoff, R. (2005). Simpler Syntax. Oxford: Oxford University Press.

DEMONTE, V. (1982). La subordinación sustantiva. Madrid: Cátedra.

DEMONTE, V. \& Fernández Soriano, O. (2004). "Features in comp and syntactic variation: the case of '(de)queísmo' in Spanish" in Lingua (www.sciencedirect.com) Articles in press.

DEL MORAL, C. (2004). Grammaticalization of spanish 'de': reanalysis of dequeísmo in Southern Cone Dialects. Urbana-Champaign: University of Illinois.

DELBECQUE, N. (2008). "Spanish dequeísmo: Part/Whole alternation and viewing arrangement” in B. Lewandowska-Tomaszczyk (Ed.). Asymmetric Events. Amsterdam/ Philadelphia: Benjamins Publishing Company.

DE MELLO, G. (1995). "El dequeísmo en el español hablado contemporáneo: un caso de independencia semántica” in Hispanic Linguistics 6/7. pp. 117-152.

DEMONTE, V. (2000). “Gramática, variación y norma. Una tipología” en Estudios hispáni$\cos 17: 12$; pp. 3-49.

EGUREN, L. y Soriano, O. (2004). Introducción a una sintaxis minimalista. Madrid: Gredos.

ESCOBAR, A. (1987). Cambios en la sociedad y en el habla "limeña". Documento de trabajo № 1. Lima: IEP.

GUIRADO, K. (2006). “Deixis proposicional en el habla de Caracas: un análisis cuantitativo del (de)queísmo" en Boletin de Lingüística 18, 26.

HJELMSLEV, L. (1976). Sistema y cambio lingüístico. Madrid: Gredos.

JACKENDOFF, R. (2010). Fundamentos del lenguaje. México: FCE.

KIPARSKY, P. \& Kiparsky, C. (1967). "Fact” in Steinberg, D. \& Jakobovitz, L. (eds.) (1971). Semantics. An Interdisciplinary Reader in Philosophy, Linguistics and Psychology. Cambridge: Cambridge University Press. 
MCLAUCHLAN, J. (1982). "Dequeísmo y queísmo en el habla culta de Lima” en Lexis 6, $1 ;$ pp. 11-55.

MORENO FERNÁNDEZ, F. (1998). Principios de sociolingüística y sociología del lenguaje. Barcelona: Ariel.

LABOV, W. (2001). Principles of Linguistic Change: Social Factors. Malden, MA: Blackwell Publishers.

LANGACKER, R. (2000). Grammar and Conceptualization. Berlín/New York: Mouton de Gruyter.

MILLÁN CH., A. (1988). "Suplemento y dequeísmo: proyección didáctica” en Cauce, Revista de Filología y su didáctica. 11, pp. 137-190.

MILLÁN CH. A. (1992). "Dequeísmo y queísmo en la Escuela Universitaria de Magisterio de Sevilla” en Cauce, Revista de Filología y su didáctica. 14-15, pp. 135-170.

MILLÁN CH. A. (1999-2000). "Queísmo y dequeísmo en los alumnos de la Facultad de Filología de la Universidad de Sevilla” en Cauce, Revista de Filología y su didáctica. 22-23, pp. 495-518.

NÁÑEZ FERNÁNDEZ, E. (1984). “Sobre dequeísmo” en Revista de Filología Románica, II, pp. 238-248.

NAVARRO, M. (2005). "El dequeísmo en el habla de Valencia”. Ponencia presentada en la XVIII Jornadas Linguíísticas de la ALFAL. Caracas. Universidad Central de Venezuela.

NEWMEYER, F. (1998). Language Form and Language Function. Cambridge, MA: MIT Press.

NEWMEYER, F. (2001). "Deconstructing grammaticalization” in Language Sciences 23. 187-229.

NOONAN, M. (1979). Complementation. New York: State University of New York at Buffalo.

PINKER, S. (1999). El instinto del lenguaje. Madrid: Alianza Editorial.

RABANALES, A. (2005). "Queísmo y dequeísmo en el español de Chile” en Onomázein 12, pp. 23-53.

REAL ACADEMIA ESPAÑOLA (2005). Diccionario panhispánico de dudas. Bogotá: Aguilar, Altea, Taurus, Alfaguara.

REAL ACADEMIA ESPAÑOLA (2009). Nueva gramática de la lengua española. Sintaxis II. Madrid: Espasa.

SÁNCHEZ ARROBA, M. E. (2001). "Gramaticalización y dequeísmo en el español de Lima” en Mercurio Peruano. Revista de Humanidades, 514. pp. 44-56.

SCHWENTER, S. (1999). "Evidentiality in Spanish morphosyntax: A reanalysis of (de) queísmo”. En Serrano, María José (ed.). 1999. Estudios de variación sintáctica, Madrid: Iberoamericana.

SMOLENSKY P. \& Legendre, G. (2006). The Harmonic Mind. From Neural Computation to Optimality-Theoretic Grammar. Cambridge MA: Massachusetts Institute of Technology. 